7. Reprod. Fert. (1972) 28, 269-272

\title{
ALTERATION OF UTERINE MOTILITY IN THE EWE BY AN INTRAUTERINE DEVICE
}

\author{
G. H. SPILMAN,* G. R. HOWE AND D. L. BLACK \\ Laboratory for Reproductive Physiology, Department of Veterinary and Animal Sciences, \\ University of Massachusetts, Amherst, Massachusetts 01002 U.S.A.
}

(Received 8th June 1971, accepted 15th September 1971)

Hawk (1967) reported that an intrauterine device (IUD) in one uterine horn blocked sperm transport, and thus fertilization, on both sides of the ovine reproductive tract. Although this effect seemed to be due to a change in uterine motility, attempts to counteract the contraceptive effect of an IUD were unsuccessful (Warren \& Hawk, 1968). Furthermore, it was reported that an IUD altered uterine activity in vitro only in ovariectomized animals (Brinsfield \& Hawk, 1968). Brinsfield \& Hawk (1969) and Mann (1969) have observed that the direction of uterine contractions is reversed in IUD-bearing animals. The present study was undertaken to determine if an IUD caused changes in the amplitude of uterine contractions as well as a change in the direction of contractions. Preliminary data are also presented which indicate that transection of the uterine segment containing the IUD reverses its contraceptive effect.

Latex micro-balloons, attached to a length of polyethylene tubing, were placed in the myometrium of the anterior portion of both uterine horns in four control ewes and four ewes bearing a polyethylene spiral IUD (Spilman, Duby \& Black, 1970) in only one horn. The tubing was brought out through a stab wound in the flank and secured in a cassette sutured to the animal. After filling the micro-balloon and tubing with distilled water, recordings of uterine motility were made during three or four successive oestrous cycles in unanaesthetized animals. Thus, repeated observations were made in the same animals for as long as 68 days. This technique has the advantage that measurements can be made in vivo from the same animals throughout the oestrous cycle without the confounding effects of repeated surgery and anaesthesia. Uterine activity was recorded for 20 to $60 \mathrm{~min}$ at each recording session using a Sanborn 964 recorder and pressure transducer, Model 267 B. To quantify the recorded uterine activity, the area under the curves was measured during a representative 3-min interval and grouped into three periods of the oestrous cycle. Initially, five randomly selected 3-min intervals of each recording were measured. There was no difference in the measured areas for these five intervals; therefore, only one 3-min interval was routinely measured in subsequent recordings. The areas were analysed by analysis of variance and Duncan's multiple-range test (Steel \& Torrie, 1960).

There was no difference $(P>0.05)$ in the mean uterine activity between the

* Present address: Worcester Foundation for Experimental Biology, Shrewsbury, Massachusetts 01545. 
right and left uterine horns within animals indicating that both uterine horns in control animals contract in a similar manner. However, the uterine horns did not necessarily contract synchronously. Furthermore, the presence of an IUD in only one uterine horn altered motility on both sides of the tract equally. This agrees with the observation (Hawk, 1967) that a unilateral IUD in the ewe affects sperm transport on both sides of the tract. Mean values of uterine activity for control and IUD-bearing animals are presented in Table 1. Periods 1 and 2 were not significantly different in control animals; however, both were greater than the activity during Period 3. Considering only animals bearing IUDs, uterine activity during Period 1 was greater than during Periods 2 and 3 . Comparing control with IUD-bearing animals, an IUD in one uterine lumen resulted in an increase in myometrial activity during all three periods. This increase was significant $(P<0.05)$ only during Period 1 . There was a relationship between the stage of the oestrous cycle and the effect an IUD had on uterine motility. Myometrial activity was increased by the presence of the IUD

TABLE 1

EFFEGT OF AN INTRAUTERINE DEVICE ON UTERINE MOTILITY

\begin{tabular}{l|c|c}
\hline & Control animals & IUD animals \\
\hline Period 1 (Days 1 to 4) & $48 \cdot 8+5 \cdot 9:$ & $\begin{array}{c}(26 \cdot 5)^{*} \\
(26)\end{array}$ \\
Period 2 (Days 5 to 10) & $35 \cdot 7 \pm 7 \cdot 1 \mathrm{a}$ & $41 \cdot 7 \pm 6 \cdot 2 \mathrm{~b}$ \\
& $(18)$ & $(24)$ \\
Period 3 (Days 11 to 17) & $20 \cdot 8 \pm 6 \cdot 3_{\mathrm{b}}^{\mathrm{a}}$ & $27 \cdot 3 \pm 6 \cdot 44_{\mathrm{b}}^{\mathrm{a}}$ \\
& $(23)$ & $(22)$ \\
\hline
\end{tabular}

Day $1=1$ st day of oestrus. Values expressed as mean areas under the curve \pm standard error.

* Number of observations; one observation $=$ area under the curve during a 3-min interval. Observations were made during successive oestrous cycles.

a,b Row means with different superscripts and column means with different subscripts are significantly different $(P<0 \cdot 05)$.

only on the day of oestrus and the 3 following days. Thus, an IUD exerted its effect only when spermatozoa would be expected in the female tract after mating. After a decrease in uterine activity immediately following oestrus, there was a transient increase between Days 6 and 9 of the cycle. This was observed in $60 \%$ of the cycles in both control and IUD-bearing animals, and may be related to an increase in the urinary excretion of oestrogens at a similar time (Plotka \& Erb, 1969).

Previous reports using anaesthetized animals (Brinsfield \& Hawk, 1969; Mann, 1969) demonstrated that an IUD caused a reversal in the direction of uterine contractions at oestrus. By making measurements of uterine activity in unanaesthetized animals throughout the oestrous cycle, we have shown that an IUD also increases myometrial activity. This effect was observed only during 
oestrus; the IUD seemed to exert no effect on uterine motility during the luteal phase of the cycle. Furthermore, the presence of an IUD in only one uterine horn increased the activity of both horns equally. It was reported (Brinsfield, Clark, Gerich \& Hawk, 1970) that an IUD also increased the phagocytosis of spermatozoa in the uterus. It seems likely, therefore, that the complete block to fertilization observed in IUD-bearing ewes is due to at least three factors (reversal in direction of contractions, increase in myometrial activity, increased phagocytosis of spermatozoa) working together to inhibit normal sperm transport.

Nine additional unilaterally ovariectomized ewes were fitted with an IUD in the uterine horn contralateral to the remaining ovary, so that the IUD offered no physical barrier to the passage of spermatozoa to the potential site of fertilization. In five animals, the area containing the device was transected by cutting across the uterine horn anterior and posterior to the IUD, and also cutting through the mesometrium adjacent to the device (Moore \& Nalbandov, 1953). The uterine segment was then sutured back in place with 5-0 cat gut. The other four animals served as control IUD-bearing animals. Natural matings were begun on the second oestrus following surgery.

One five-cell embryo was recovered from a control IUD-bearing animal killed $48 \mathrm{hr}$ after mating; there were no spermatozoa visible in the zona pellucida. One unfertilized ovum was recovered from each of two other control IUDbearing animals slaughtered at a similar time. The fourth ewe was mated at three successive periods of oestrus and was not pregnant when slaughtered. Two eight-cell embryos were recovered from one of the transected IUD-bearing animals. Both embryos had accessory spermatozoa (four and six) in the zonae pellucidae. Two other ewes in the group contained normal, apparently healthy fetuses when slaughtered 45 and 64 days after mating. The IUDs in the two remaining ewes in the transected group had moved out of the transected area; these two animals have, therefore, been included in the control group. One unfertilized ovum was recovered from each of these animals $48 \mathrm{hr}$ after mating. The responses of the control and transected groups were compared in a $2 \times 2$ contingency table. Chi-square was equal to $3.26(0 \cdot 10>P>0.05)$, indicating that transection of the uterine segment containing the IUD increased fertility.

At slaughter, the transected segment appeared to be completely revascularized. The suture lines on the uterine horn were the only gross evidence of transection. There was no evidence of infection or inflammation in the uterine lumen. In most animals, the endometrium had pushed up into the IUD and formed polyp-like bodies within the device. Microscopic section of these polyps did not reveal any unusual structure. There were a few polymorphonuclear leucocytes in the vessels and connective tissue of both uterine horns.

Transection of the area of the uterus containing the IUD seems to reverse the contraceptive effect of the device. One possible explanation for this is that the presence of an IUD elicits a nervous response resulting in an alteration of uterine motility, and that this response is blocked by transection of the uterus.

This work was supported in part by Northeast Regional Research Project, NE-41. One of us (G.H.S.) was supported by an NDEA Title IV Fellowship. 


\section{REFERENCES}

Brinsfield, T. H., Glark, M. V., Gerich, V. \& Hawk, H. W. (1970) Disappearance and phagocytosis of sperm in sheep uteri. (Abstract). F. Anim. Sci. 31, 218.

Brinsfield, T. H. \& Hawk, H. W. (1968) Stimulation by intra-uterine devices of motility of sheep myometrium. F. Reprod. Fert. 16, 129.

Brinsfield, T. H. \& HAWK, H. W. (1969) Modification of the direction of uterine contractions by intra-uterine devices in the ewe. 7 . Reprod. Fert. 18, 535.

Hawk, H. W. (1967) Investigations into the anti-fertility effect of intra-uterine devices in the ewe. $\mathcal{F}$. Reprod. Fert. 14, 49.

Mann, L. I. (1969) Effect of the IUCD on uterine motility in the ewe. Fert. Steril. 20, 951.

Moore, W. W. \& Nalbandov, A. V. (1953) Neurogenic effects of uterine distention on the estrous cycle of the ewe. Endocrinology, 53,1.

Plotka, E. D. \& ERB, R. E. (1969) Identification and excretion of estrogen in urine during the estrous cycle of the ewe. F. Anim. Sci. 29, 934.

Spilman, G. H., Duby, R. T. \& Black, D. L. (1970) Effect of an intrauterine device on sheep oviduct fluids: chemical composition and stimulation of spermatozoan respiration in vitro. Biol. Reprod. 3,76 .

Steel, R. G. D. \& Torrie, J. H. (1960) Principles and procedures of statistics. McGraw-Hill, New York.

WARREN, J. E. \& HAWK, H. W. (1968) Attempts to overcome the antifertility effect of intrauterine plastic spirals in the ewe. $\mathcal{F}$. Anim. Sci. 27, 131. 